\title{
Therapeutic potential of stem cells expressing suicide genes that selectively target human breast cancer cells: Evidence that they exert tumoricidal effects via tumor tropism (Review)
}

\author{
BO-RIM YI ${ }^{1}$, KELVIN J. CHOI ${ }^{2}$, SEUNG U. $\mathrm{KIM}^{3,4}$ and KYUNG-CHUL CHOI ${ }^{1}$ \\ ${ }^{1}$ Laboratory of Veterinary Biochemistry and Immunology, College of Veterinary Medicine, Chungbuk \\ National University, Cheongju, Chungbuk, Republic of Korea; Departments of ${ }^{2}$ Chemistry and \\ ${ }^{3}$ Medicine, University of British Columbia, Vancouver, British Columbia, Canada; ${ }^{4}$ Medical \\ Research Institute, Chung-Ang University College of Medicine, Seoul, Republic of Korea
}

Received March 21, 2012; Accepted May 30, 2012

DOI: 10.3892/ijo.2012.1523

\begin{abstract}
Breast cancer is the most prevalent cancer in women worldwide and is classified into ductal and lobular carcinoma. Breast cancer as well as lobular carcinoma is associated with various risk factors such as gender, age, female hormone exposure, ethnicity, family history and genetic risk factor-associated genes. Genes associated with a high risk of developing breast cancer include BRCA1, BRCA2, p53, PTEN, $C H E K 2$ and $A T M$. Surgery, chemotherapy, radiotherapy and hormone therapy are used to treat breast cancer but these therapies, except for surgery, have many side-effects such as alopecia, anesthesia, diarrhea and arthralgia. Gene-directed enzyme/prodrug therapy (GEPT) or suicide gene therapy, may improve the therapeutic efficacy of conventional cancer radiotherapy and chemotherapy without side-effects. GEPT most often involves the use of a viral vector to deliver a gene not found in mammalian cells and that produces enzymes which can convert a relatively non-toxic prodrug into a toxic agent. Examples of these systems include cytosine deaminase/5fluorocytosine (CD/5-FC), carboxyl esterase/irinotecan (CE/CPT-11), and thymidine kinase/ganciclovir (TK/GCV). Recently, therapies based on genetically engineered stem cells (GESTECs) using a GEPT system have received a great deal of attention for their clinical and therapeutic potential to treat breast cancer. In this review, we discuss the potential of GESTECs via tumor tropism effects and therapeutic efficacy against several different types of cancer cells. GESTECs represent a useful tool for treating breast cancer without inducing injuries associated with conventional therapeutic modalities.
\end{abstract}

Correspondence to: Professor Kyung-Chul Choi, Laboratory of Veterinary Biochemistry and Immunology, College of Veterinary Medicine, Chungbuk National University, Cheongju, Chungbuk 361-763, Republic of Korea

E-mail:kchoi@cbu.ac.kr

Key words: gene-direct enzyme/prodrug therapy, stem cell therapy, cytosine deaminase, carboxyl esterase, thymidine kinase, breast cancer

\section{Contents}

1. Breast cancer

2. GEPT using various prodrug/enzymes

3. Genetically engineered stem cell (GESTEC)-based therapy for treating breast cancer

4. Conclusions

\section{Breast cancer}

Overview. Breast cancer is the most frequently diagnosed cancer and the leading cause of cancer mortality in women, accounting for $23 \%$ of all cancer cases and $14 \%$ of all cases of cancer mortality (1). The breasts are composed of fat, glandular, and connective (fibrous) tissues, and contain several lobes which are divided into lobules that end in milk glands. Tiny ducts run from the glands, converge, and end in the nipple. Breast cancer changes the size or shape of the breast and can be separated into two histopathological categories: ductal and lobular carcinoma (2). Additionally, these carcinomas are further divided into in situ and invasive carcinomas according to whether the tumor is confined to the glandular component of the organ or whether it has invaded the stroma (3). Ductal carcinoma represents $80 \%$ of breast cancer cases and presumably originates from malignant epithelial cells within the ducts or tubes that carry milk to the nipple from the breast (4). Lobular carcinoma is a less common form of breast cancer that commences in the milk-producing lobules of the breast (5). This type of carcinoma is composed of acini filled with a small, round, polygonal or cuboidal cells (6).

Breast cancer progression includes five stages defined according to tumor size, spread to the lymph nodes, and metastasis (spread to a more distant part of the body) (7). Stage 0 is a pre-cancerous state in which the cancerous cells have not spread outside of the milk-producing lobules or ducts. Lesions in this stage are also referred to as ductal carcinoma in situ (DCIS) and lobular carcinoma in situ (LCIS) (8). DCIS is generally categorized into the five most common architectural subtypes, including papillary, micropapillary, cribriform solid, 
and comedo (9). Stages I to III are characterized by lesions within the breast or regional lymph nodes; these stages are based on the size of the tumor and the spread to the lymph nodes (10). Finally, stage IV is metastatic cancer that has spread to other organs of the body (i.e., lungs, bones, liver, or brain) (11). Although breast cancer is the most frequently diagnosed cancer and the leading cause of cancer mortality in women, if detected during the early stages it can be treated successfully by surgery or chemotherapy (12).

Causes. Variable risk factors for breast cancer include gender, age, female hormone exposure, ethnicity, obesity, family history of breast cancer, genetic risk factors, and many abnormal conditions of the breast $(13,14)$. Being female is the main risk factor for developing breast cancer since women have significantly more breast cells than men. Nevertheless, men can also develop breast cancer but they account for $<1 \%$ of all breast cancer cases (15). Clinically, breast cancer in men is similar to that in women and is also affected by hormonal, genetic, and environmental factors (16).

In women, cells in the breast are exposed to growthstimulating female hormones including estrogen (E2) and progesterone (P4) (17). E2 stimulates breast cell division which can increase the risk of permanent DNA damage (18). The growth factor transforming growth factor- $\alpha$ (TGF- $\alpha$ ) can also affect cell division, and overexpression of this factor is associated with increased cell division in breast cancer (19).

The risk of developing breast cancer increases with age and doubles every 10 years until menopause (20). Age is the strongest risk factor for breast cancer after gender (21). There are also numerous genetic risk factors for breast cancer. Numerous cases of cancer begin when one or more genes in a cell mutate, thereby producing an abnormal protein or no protein at all (22). Production of an abnormal protein and lack of protein production may cause cells to divide uncontrollably and become cancerous (23). The normal function of genetic risk factor-associated genes is the suppression of tumorigenesis. Genes associated with a high risk of developing breast cancer include BRCA1, BRCA2, p53, PTEN, STK11, CHEK2, and ATM $(24,25)$. Finally, various other factors such as medical history, life style, dense breast tissue, alcohol intake, and smoking can promote the development of breast cancer (26).

BRCA1 and BRCA2. Mutation of breast cancer type 1 and 2 susceptibility proteins (BRCA1 and BRCA2) cause most hereditary breast or ovarian cancer syndromes. BRCA geneassociated mutations might also be caused by Li-Fraumeni-like syndrome (LFS) $(27,28)$. Mutation of these genes confers a $43-84 \%$ risk of breast cancer by the age of 50-70 in women $(29,30)$. It is now clear that the normal protein products of BRCA1 and BRCA2 are tumor suppressors (31). BRCA1 is located on chromosome 17 . The BRCA1 protein acts as a hub protein that promotes genomic stability and DNA repair by its involvement in homologous recombination and nucleotide excision repair, DNA damage response and cell cycle check point control, chromatin remodeling, transcriptional regulation, and protein ubiquitylation (32). BRCA2 is located on chromosome 13 . The BRCA2 protein plays an important role in maintaining genomic stability via homologous recombination, both during meiosis and repair of double-strand breaks (33). Both BRCA1 and BRCA2 mutations have been found more often in patients with high grade breast cancer compared to age-matched control patients (34). However, tumors with BRCA1 mutations have high mitotic counts and ones with BRCA2 mutations mostly contain less tubular structures. Furthermore, BRCA2 mutations are associated with a more extensive intraductal component than BRCA1 mutations, and increase the risks for certain childhood tumors (35).

p53. p53 is a known tumor suppressor gene encoding a sequence-specific transcriptional regulator which controls cell cycle progression, senescence, differentiation, DNA repair, and apoptosis (36). This gene has a major function in responding to cellular stress factors, such as DNA damage and hypoxia, resulting in a cascade of events that reduces the risk of cancer and prevents tumor development (37). Moreover, p53 mutations have been observed in all the major histogenetic groups, including cancer of the colon, stomach, breast, ovary, and esophagus, and account for $>50 \%$ of all cancer cases (38). A point mutation in the $p 53$ gene has been found between exon 4 and 10 that is located within the DNA binding domain of the p53 protein (39). A somatic mutation in the $p 53$ gene is the most common genetic change found in $20-35 \%$ of breast cancers and is associated with poor prognosis $(40,41)$. A significant number of breast cancer cases is linked with BRCA1 mutations that may affect p53 function, and activates a p53-dependent response (42). Furthermore, high expression of p53 is more frequently found in estrogen and progesterone receptor-negative breast cancers $(43,44)$ and is also associated with a high proliferation rate, high histological grade, aneuploidy, and decreased survival rates (45).

PTEN. Phosphatase and tensin homolog (PTEN) encoded by the PTEN gene in humans has been identified as a tumor suppressor in many types of cancer (46). This lipid phosphatase is involved in cell cycle regulation and prevents cells from growing and dividing too rapidly (47). The phosphatidylinositol $(3,4,5)$-trisphosphate (PIP3) kinase-protein kinase B (PI3K-AKT) pathway is activated in human cancers. Activated PI3K is phosphorylated phosphatidylinositol-4,5-bisphosphate (PIP2) to generate PIP3 $(48,49)$. PIP3 activates Akt and is an important lipid second messenger that has a role in tumorigenesis (50). On the other hand, the PTEN protein, the key agonist of PI3K-AKT signaling, is inactivated in a broad spectrum of human cancers (51). However, somatic PTEN deletions and mutations have been observed in breast, brain, prostate, and kidney cancer cell lines as well as in several primary tumors such as endometrial carcinomas, malignant gliomas, melanomas, and thyroid tumors $(52,53)$. In particular, Cowden syndrome patients have a germ line PTEN mutation, and an increasing amount of data have associated PTEN loss with breast cancer (5-21\%) (54). It has also been reported that suppression of PTEN function increases breast cancer chemotherapeutic drug resistance $(55,56)$. Some cell lines with mutated PTEN have an abnormal cell cycle and defective apoptotic responses (57).

CHEK2 and ATM. The product of the cell cycle checkpoint kinase 2 (CHEK2) gene responds to DNA damage (doublestrand breaks) in a dynamic, multistep process and protects genomic integrity (58). CHEK2 is a serine/threonine protein kinase found in humans and yeast. Activation of CHEK2 is regulated through phosphorylation by ataxia telangiectasia mutated (ATM) in both yeast and humans (59). ATM belongs 
to the PI3K-related protein kinase (PIKK) family and is responsible for the immediate and rapid response to doublestrand breaks $(60,61)$. However, mutation of this gene causes the development of ataxia-telangiectasia (AT), a neurodegenerative disease (62). The relationship between AT and breast cancer was first reported 20 years ago with the observation that relatives of AT patients have an increased risk of breast cancer (63).

Activated CHEK2 phosphorylates critical cell cycle proteins that results in the stabilization of p53 and the inhibition of $\mathrm{Cdc} 25 \mathrm{C}$ phosphatase, leading to $\mathrm{G} 1$ cell-cycle arrest along with the prevention of entry into mitosis and the activation of DNA repair (64). This kinase also phosphorylates BRCA1, resulting in get back DNA damage (65). Mutations in the $C H E K 2$ gene, including truncation variant $1100 \mathrm{delC}$, have been reported to increase breast cancer risk by up to two-fold and may vary according to the Li-Fraumeni syndrome as well as breast cancer (66). Susceptibility to cancer due to this gene variation was first described in 1999, and the products of the CHEK2 and ATM genes are now known to be involved in p53 inactivation (67).

Breast cancer treatments. Breast cancer is almost always treated with surgery, chemotherapy, radiotherapy, and hormone therapy. Surgical procedures, called mastectomy or lumpectomy, have a role in treating most patients with breast cancer (68). During these procedures, the cancerous lesions are removed from the breast along with some of the surrounding tissue. For this reason, the number of patients who receive breast implants after undergoing a mastectomy has increased (69). After performing surgery to treat breast cancer, radiation is used as an adjuvant treatment depending on the disease stage (70).

Hormonal therapy, including administration of tamoxifen, raloxifene (a selective estrogen receptor modulator, SERM), and aromatase inhibitors (AIs), increases the survival rate of hormone-sensitive breast cancer patients (71). Treatment of breast cancer patients with AIs is more effective than tamoxifen although patients receiving AIs have a higher prevalence of osteoporosis, bone fractures, and musculoskeletal symptoms, particularly joint pain and stiffness (72).

Chemotherapy is given to slow or stop the growth of cancer cells. For this, 5-fluorouracil (5-FU), cyclophosphamide, methotrexate, anthracyclines, trastuzumab, and taxanes are primarily used (73). If the breast cancer is positive for human epidermal growth factor receptor 2 (HER-2), it is treated with trastuzumab (herceptin) which targets the HER-2 oncogene (74). 5-FU has also been the preferred chemotherapeutic agent for treating a majority of solid tumors, including gastric and colon cancers (75). However, serious side-effects such as alopecia, anesthesia, diarrhea, and arthralgia, as well as high dose requirements have limited the use of these chemotherapeutic agents (76).

\section{GEPT using various prodrug/enzymes}

Gene-direct enzyme/prodrug therapy (GEPT), or suicide gene therapy, aims to improve the therapeutic efficacy of conventional cancer radio- and chemo-therapy without side-effects (77,78). This system is a novel approach with the potential to selectively eradicate tumor cells (79). For this, an exogenous suicide enzyme gene is delivered to tumor cells (80). GEPT systems most often involve the use of a viral vector (adeno-, lenti-, or retroviral vectors) to deliver a gene not normally found in mammalian cells that produces enzymes which, when expressed, can convert a relatively non-toxic prodrug into a toxic agent $(81,82)$.

GEPT systems involve two separate events: direct cell death and cell death via the bystander effect (83). The viral vectors transfected into the target tumor cells induced cell death (84). Direct cell death is caused by expression of the viral DNA in the targeted tumor cells (85). Next, cell death via the bystander effect is induced by the gene transfer of a viral or bacterial enzyme into targeted tumor cells. The enzymes convert an inactive prodrug into a short-lived toxic metabolite, leading to the death of cells surrounding the targeted tumor cells (86). Prodrugs can be defined as pharmacologically inactive derivatives which require chemical transformation for the release or conversion into the active drug (87). A suicide enzyme converts the administered non-toxic prodrug into an active drug which subsequently kills tumor cells but not normal tissues (88). Several types of suicidal genes have been studied and used for therapeutic purposes (82).

An advantage of these GEPT systems derives from the local bystander effect through which more wide-spread cell death is achieved without the need to express the gene in all cells (89). This is due to the ability of the toxic metabolite to diffuse freely across cells membranes or via gap junctions (90). Currently, a large number of enzyme/prodrug systems have been developed for GEPT. These include the cytosine deaminase/5-fluorocytosine (CD/5-FC), carboxyl esterase/ irinotecan (CE/CPT-11), and thymidine kinase/ganciclovir (TK/GCV) systems (91).

Cytosine deaminase/5-fluorocytosine (CD/5-FC). One of the most widely used suicidal genes is bacterial or yeast CD (from Escherichia coli or Saccharomyces cerevisiae) (92). Both bacterial and yeast CD have been shown to inhibit tumor growth (93). The enzyme encoded by the $C D$ gene catalyzes the conversion of cytosine into uracil; it is an important member of the pyrimidine salvage pathway in prokaryotes and fungi, but is not present in multicellular eukaryotes (mammalian cells) $(94,95) .5-\mathrm{FC}$ is a hydrophilic antifungal drug with low toxicity in humans (96). CD catalyzes the conversion of the non-cytotoxic prodrug 5-fluorocytosine (5-FC) into the cytotoxic chemotherapeutic agent 5-FU, resulting in antitumor activity (97). CD is currently being explored for use in gene therapy applications against solid tumors due to this activity (98).

The CD/5-FC system is very effective for treating human cancers as non-toxic 5-FC systemically administered can be converted into the cytotoxic agent 5 -FU by the $C D$ gene product located in the vicinity of the cancer (99). Deamination of the 5-FC prodrug by CD results in the formation of two toxic metabolites: 5-fluorodeoxyuridine monophosphate (FdUMP) and 5-fluorouridine triphosphate (FURTP). FdUMP is a potent inhibitor of thymidylate synthetase (TS) which is an enzyme essential for DNA synthesis. This compound impairs DNA synthesis and promotes apoptosis in bacteria and tumor cells $(100,101)$. 


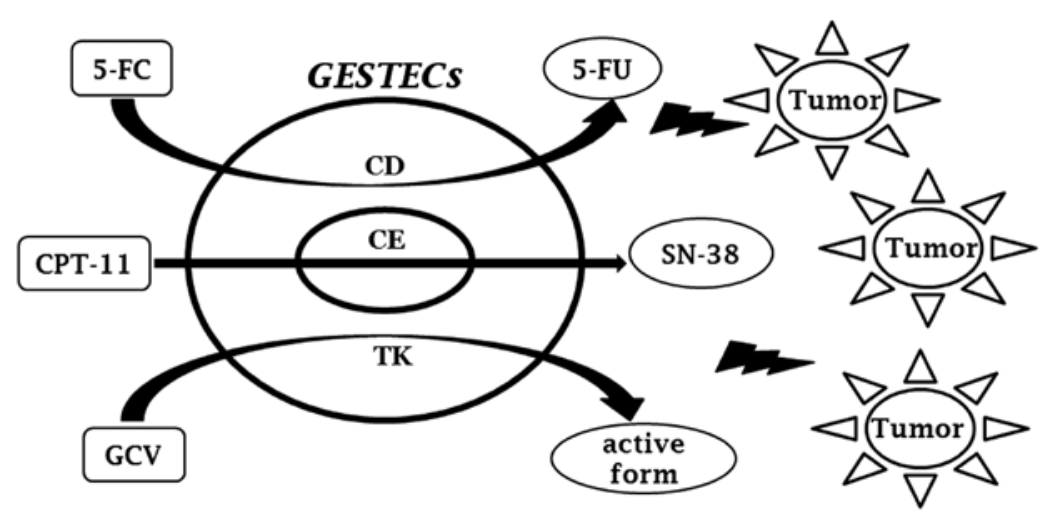

Figure 1. Schematic of genetically engineered stem cell (GESTEC)-based therapy. GESTECs are immortalized by retroviral vectors and contain suicide genes such as ones encoding cytosine deaminase (CD), carboxyl esterase (CE), and thymidine kinase (TK). CD converts the prodrug 5-fluorocytosine (5-FC) into a toxic agent, 5-fluorouracil (5-FU), which inhibits RNA and DNA synthesis. CPT-11 is a prodrug converted by CE into its active form, SN-38, which is a potent mammalian topoisomerase I inhibitor. Finally, the TK gene is found in herpes simplex virus (HSV). The product of this gene converts non-toxic ganciclovir into its toxic active form. These GESTECs exert tumor-tropism effects and may be used to treat several types of tumors.

Carboxyl esterase/irinotecan (CE/CPT-11). CE enzyme is a serine esterase found in a variety of tissues from numerous mammalian species (102). This enzyme plays a critical role in increasing the solubility and bio-availability of therapeutic agents $(103,104)$. It is cleaved into the bulky piperidino sidechain of 7-ethyl-10-[4-(1-piperidino)-1-piperidino] carbonyl-oxycamptothecin (irinotecan or CPT-11). The anticancer agent CPT-11 is a prodrug that is activated by CE to generate the active form 7-ethyl-10-hydroxycamptothecin (SN-38) $(105,106)$. SN-38 is a strong mammalian topoisomerase I inhibitor that is 1,000 -fold more potent than CPT-11. This agent induces the accumulation of double-strand DNA breaks in actively dividing cancer cells (107).

Thymidine kinase/ganciclovir (TK/GCV). The most common GEPT uses the herpes simplex type-1 thymidine kinase enzyme (HSV-TK) in conjunction with a variety of guanosinebased prodrugs, compounds originally developed as antiviral agents (108). The HSV-TK enzyme converts to the prodrug into its monophosphate form, GCV, which is then further converted into the toxic triphosphates form, an intermediary metabolite, by cellular enzymes $(109,110)$. These actions cause cell death by inhibiting the incorporation of dGTP into DNA without preventing progression through the S-phase; chain elongation is also inhibited (111).

\section{Genetically engineered stem cell (GESTEC)-based therapy for treating breast cancer}

Toxicity of anticancer agents to normal cells is a major limitation of breast cancer therapy (112). Therefore, stem cells have recently received a great deal of attention for their clinical and therapeutic potential to treat breast cancer. Stem cells are capable of continuous self-renewal and differentiation $(113,114)$. A variety of stem cells, such as neural stem cells (NSCs), neural progenitor cells, and mesenchymal stem cells (MSCs) from bone marrow or adipose tissue, have been found to exert tumor-tropism effects (115). This ability makes these cells attractive for use as targeted delivery vectors for antitumor therapies $(87,88,99,116-117)$. The tumor-tropism effects of stem cells are mediated by multiple cell-surface and secreted proteins, and candidate cytokines/receptors including stromal cell-derived factor-1 (SDF-1)/CXCR4, stem cell factor (SCF)/c-Kit, hepatocyte growth factor (HGF)/Met, vascular endothelial growth factor (VEGF)/VEGF receptor (VEGFR), monocyte chemoattractant protein-1 (MCP-1)/CCP, and highmobility group box1 (HMGB1)/RAGE $(87,88,99,117,118)$. In addition, NSCs appear to migrate to cancer cells more efficiently compared to MSCs. Although both NSCs and MSCs have a tumor tropic effect, NSCs (50-100\% of total cell number) were proven to display greater tropism towards tumor cells than MSCs (40-75\% of total cell number) (119).

The field of NSC research in recent years has seen major advances and efforts have been made to develop their use in potential stem cell-based transplantation therapies (120). NSCs can be used to generate all major mature neural cell types such as neurons, oligodendrocytes, glial cells and cells of neuronal lineages (121). The fetal brain, characterized by active neurogenesis, is thought to be a promising source of therapeutic NSCs (122). Previous studies have shown that NSCs derived from human fetal telencephalon can be used for GESTEC-based therapy for treating several different cancers as well as brain diseases $(87,88,99)$. As this is based on a GEPT system, it involves the expression of several suicide enzymes (Fig. 1). In previous studies, GESTECs were immortalized by using retrovirus v-myc and suicide genes such as $C D, C E$, and $T K$. Therapeutic efficacy has been assessed by monitoring tumor-tropism in a brain cancer animal model (123).

In other studies, NSCs expressing $C D$ or $C E$ genes in an animal model of breast cancer brain metastasis were found to significantly reduce breast tumor mass in the brain (124). This demonstrated the therapeutic efficacy of GESTECs in the presence of a prodrug (114). Brain metastases originate from cells that do not reside in the brain. This suggests that breast tumor metastases in the brain attract GESTECs as well as the original brain tumor. The therapeutic efficacy of GESTECs for treating several other types of cancer cells (i.e., ovarian, endometrial, and lung cancer cells) as well as brain tumors, including medulloblastomas and gliomas has also been demonstrated in vitro. Furthermore, therapies using GESTECs may use as breast cancer treatment in vitro and in vivo. 


\section{Conclusions}

Breast cancer is the leading cause of cancer related mortality among women worldwide. Several gene mutations lead to the development of breast cancer including ductal and lobular breast carcinoma. Chemo-, hormone-, and radio-therapies are used to treat breast cancer but these therapies are associated with many side-effects. For this reason, GEPT systems have been examined as a novel anticancer therapeutic approach with the potential to selectively eradicate tumor cells. Prodrugs used for GEPT are primarily antimetabolites that require cell cycling (S phase) to induce cytotoxicity and are not active against normal cells. These systems may involve the use of NSCs which express suicide genes and have the ability to selectively migrate to tumors. In summary, GESTECs using GEPT systems may be an effective new modality for treating breast cancer as well as brain tumors without inducing injurious effects commonly associated with more conventional anticancer therapies.

\section{Acknowledgements}

This study was supported by two National Research Foundation of Korea (NRF) grants funded by the Ministry of Education, Science and Technology (MEST) of the Korean Government (no. 2010-0003093 and 2011-0015385).

\section{References}

1. Jemal A, Bray F, Center MM, Ferlay J, Ward E and Forman D Global cancer statistics. CA Cancer J Clin 61: 69-90, 2011.

2. Vincent-Salomon A and Thiery JP: Host microenvironment in breast cancer development: epithelial-mesenchymal transition in breast cancer development. Breast Cancer Res 5: 101-106, 2003.

3. Middleton LP, Tressera F, Sobel ME, Bryant BR, Alburquerque A, Grases $\mathrm{P}$ and Merino MJ: Infiltrating micropapillary carcinoma of the breast. Mod Pathol 12: 499-504, 1999.

4. Goldstein NS, Vicini FA, Kestin LL and Thomas M: Differences in the pathologic features of ductal carcinoma in situ of the breast based on patient age. Cancer 88: 2553-2560, 2000.

5. Li CI, Anderson BO, Porter P, Holt SK, Daling JR and Moe RE: Changing incidence rate of invasive lobular breast carcinoma among older women. Cancer 88: 2561-2569, 2000.

6. Lakhani SR, Audretsch W, Cleton-Jensen AM, Cutuli B, Ellis I, Eusebi V, Greco M, Houslton RS, Kuhl CK, Kurtz J, et al: The management of lobular carcinoma in situ (LCIS). Is LCIS the same as ductal carcinoma in situ (DCIS)? Eur J Cancer 42: 2205-2211, 2006.

7. Cianfrocca M and Goldstein LJ: Prognostic and predictive factors in early-stage breast cancer. Oncologist 9: 606-616, 2004.

8. Lehman CD, Gatsonis C, Kuhl CK, Hendrick RE, Pisano ED, Hanna L, Peacock S, Smazal SF, Maki DD, Julian TB, et al: MRI evaluation of the contralateral breast in women with recently diagnosed breast cancer. N Engl J Med 356: 1295-1303, 2007.

9. Skinner KA and Silverstein MJ: The management of ductal carcinoma in situ of the breast. Endocr Relat Cancer 8: 33-45, 2001.

10. Singletary SE and Connolly JL: Breast cancer staging: working with the sixth edition of the AJCC Cancer Staging Manual. CA Cancer J Clin 56: 37-50, 2006.

11. Askoxylakis V, Thieke C, Pleger ST, Most P, Tanner J, Lindel K, Katus HA, Debus J and Bischof M: Long-term survival of cancer patients compared to heart failure and stroke: a systematic review. BMC Cancer 10: 105, 2010.

12. Lv H, Pan G, Zheng G, Wu X, Ren H, Liu Y and Wen J: Expression and functions of the repressor element 1 (RE-1)-silencing transcription factor (REST) in breast cancer. J Cell Biochem 110 968-974, 2010.

13. Vogel KJ, Atchley DP, Erlichman J, Broglio KR, Ready KJ, Valero V, Amos CI, Hortobagyi GN, Lu KH and Arun B: BRCA1 and BRCA2 genetic testing in Hispanic patients: mutation prevalence and evaluation of the BRCAPRO risk assessment model. J Clin Oncol 25: 4635-4641, 2007.
14. Olsson H: Tumour biology of a breast cancer at least partly reflects the biology of the tissue/epithelial cell of origin at the time of initiation - a hypothesis. J Steroid Biochem Mol Biol 74: $345-350,2000$

15. Giordano SH, Cohen DS, Buzdar AU, Perkins G and Hortobagyi GN: Breast carcinoma in men: a population-based study. Cancer 101: 51-57, 2004.

16. Iredale R, Brain K, Williams B, France E and Gray J: The experiences of men with breast cancer in the United Kingdom. Eur J Cancer 42: 334-341, 2006.

17. Yager JD and Davidson NE: Estrogen carcinogenesis in breast cancer. N Engl J Med 354: 270-282, 2006.

18. Nass SJ and Davidson NE: The biology of breast cancer. Hematol Oncol Clin North Am 13: 311-332, 1999.

19. Antonova L, Aronson K and Mueller CR: Stress and breast cancer: from epidemiology to molecular biology. Breast Cancer Res 13: 208, 2010.

20. McTiernan A: Behavioral risk factors in breast cancer: can risk be modified? Oncologist 8: 326-334, 2003.

21. Friedenreich CM, Courneya KS and Bryant HE: Influence of physical activity in different age and life periods on the risk of breast cancer. Epidemiology 12: 604-612, 2001.

22. MacConaill LE, Campbell CD, Kehoe SM, Bass AJ, Hatton C, Niu L, Davis M, Yao K, Hanna M, Mondal C, et al: Profiling critical cancer gene mutations in clinical tumor samples. PLoS One 4: e7887, 2009.

23. Martin AM and Weber BL: Genetic and hormonal risk factors in breast cancer. J Natl Cancer Inst 92: 1126-1135, 2000.

24. Plak K, Czarnecka AM, Krawczyk T, Golik P and Bartnik E: Breast cancer as a mitochondrial disorder (Review). Oncol Rep 21: 845-851, 2009.

25. Lynch HT, Silva E, Snyder C and Lynch JF: Hereditary breast cancer: part I. Diagnosing hereditary breast cancer syndromes. Breast J 14: 3-13, 2008.

26. Singletary SE: Rating the risk factors for breast cancer. Ann Surg 237: 474-482, 2003.

27. Kadouri L, Hubert A, Rotenberg Y, Hamburger T, Sagi M, Nechushtan C, Abeliovich D and Peretz T: Cancer risks in carriers of the BRCA1/2 Ashkenazi founder mutations. J Med Genet 44: 467-471, 2007.

28. Campeau PM, Foulkes WD and Tischkowitz MD: Hereditary breast cancer: new genetic developments, new therapeutic avenues. Hum Genet 124: 31-42, 2008.

29. King MC, Marks JH and Mandell JB: Breast and ovarian cancer risks due to inherited mutations in BRCA1 and BRCA2. Science 302: 643-646, 2003

30. Thorslund T and West SC: BRCA2: a universal recombinase regulator. Oncogene 26: 7720-7730, 2007.

31. Welcsh PL and King MC: BRCA1 and BRCA2 and the genetics of breast and ovarian cancer. Hum Mol Genet 10: 705-713, 2001.

32. Narod SA and Foulkes WD: BRCA1 and BRCA2: 1994 and beyond. Nat Rev Cancer 4: 665-676, 2004.

33. Thorslund T, Esashi $\mathrm{F}$ and West SC: Interactions between human BRCA2 protein and the meiosis-specific recombinase DMC1. EMBO J 26: 2915-2922, 2007.

34. Verhoog LC, Berns EM, Brekelmans CT, Seynaeve C, MeijersHeijboer EJ and Klijn JG: Prognostic significance of germline BRCA2 mutations in hereditary breast cancer patients. J Clin Oncol 18: 119S-124S, 2000.

35. Loman N, Johannsson O, Bendahl P, Dahl N, Einbeigi Z, Gerdes A, Borg A and Olsson H: Prognosis and clinical presentation of BRCA2-associated breast cancer. Eur J Cancer 36: 1365-1373, 2000

36. Lim LY, Vidnovic N, Ellisen LW and Leong CO: Mutant p53 mediates survival of breast cancer cells. Br J Cancer 101: 1606-1612, 2009.

37. Bergamaschi D, Gasco M, Hiller L, Sullivan A, Syed N, Trigiante G, Yulug I, Merlano M, Numico G, Comino A, et al: p53 polymorphism influences response in cancer chemotherapy via modulation of p73-dependent apoptosis. Cancer Cell 3: 387-402, 2003.

38. Geisler S, Lonning PE, Aas T, Johnsen H, Fluge O, Haugen DF, Lillehaug JR, Akslen LA and Borresen-Dale AL: Influence of TP53 gene alterations and c-erbB-2 expression on the response to treatment with doxorubicin in locally advanced breast cancer. Cancer Res 61: 2505-2512, 2001.

39. Beroud $C$ and Soussi T: p53 gene mutation: software and database. Nucleic Acids Res 26: 200-204, 1998.

40. Vousden KH and Lane DP: p53 in health and disease. Nat Rev Mol Cell Biol 8: 275-283, 2007. 
41. Olivier M, Petitjean A, Marcel V, Petre A, Mounawar M, Plymoth A, de Fromentel CC and Hainaut P: Recent advances in p53 research: an interdisciplinary perspective. Cancer Gene Ther 16: 1-12, 2009.

42. Hohenstein P and Giles RH: BRCA1: a scaffold for $\mathrm{p} 53$ response? Trends Genet 19: 489-494, 2003.

43. Coutant C, Rouzier R, Qi Y, Lehmann-Che J, Bianchini G, Iwamoto T, Hortobagyi GN, Symmans WF, Uzan S, Andre F, de The $\mathrm{H}$ and Pusztai L: Distinct p53 gene signatures are needed to predict prognosis and response to chemotherapy in ER-positive and ER-negative breast cancers. Clin Cancer Res 17: 2591-2601, 2011.

44. Yamashita H, Nishio M, Toyama T, Sugiura H, Zhang Z, Kobayashi S and Iwase H: Coexistence of HER2 over-expression and 553 protein accumulation is a strong prognostic molecular marker in breast cancer. Breast Cancer Res 6: R24-30, 2004.

45. Feki $A$ and Irminger-Finger I: Mutational spectrum of p53 mutations in primary breast and ovarian tumors. Crit Rev Oncol Hematol 52: 103-116, 2004.

46. Yang J, Ren Y, Wang L, Li B, Chen Y, Zhao W, Xu W, Li T and Dai F: PTEN mutation spectrum in breast cancers and breast hyperplasia. J Cancer Res Clin Oncol 136: 1303-1311, 2010.

47. Wallace JA, Li F, Leone G and Ostrowski MC: Pten in the breast tumor microenvironment: modeling tumor-stroma coevolution. Cancer Res 71: 1203-1207, 2011.

48. Tokunaga E, Oki E, Kimura Y, Yamanaka T, Egashira A, Nishida K, Koga T, Morita M, Kakeji Y and Maehara Y: Coexistence of the loss of heterozygosity at the PTEN locus and HER 2 overexpression enhances the Akt activity thus leading to a negative progesterone receptor expression in breast carcinoma. Breast Cancer Res Treat 101: 249-257, 2007.

49. Marty B, Maire V, Gravier E, Rigaill G, Vincent-Salomon A, Kappler M, Lebigot I, Djelti F, Tourdes A, Gestraud P, et al: Frequent PTEN genomic alterations and activated phosphatidylinositol 3-kinase pathway in basal-like breast cancer cells Breast Cancer Res 10: R101, 2008.

50. Shaw RJ and Cantley LC: Ras, PI(3)K and mTOR signalling controls tumour cell growth. Nature 441: 424-430, 2006.

51. DeGraffenried LA, Fulcher L, Friedrichs WE, Grunwald V, Ray RB and Hidalgo M: Reduced PTEN expression in breast cancer cells confers susceptibility to inhibitors of the PI3 kinase/ Akt pathway. Ann Oncol 15: 1510-1516, 2004.

52. Tate G, Suzuki T and Mitsuya T: Mutation of the PTEN gene in a human hepatic angiosarcoma. Cancer Genet Cytogenet 178 : $160-162,2007$.

53. Petrocelli T and Slingerland JM: PTEN deficiency: a role in mammary carcinogenesis. Breast Cancer Res 3: 356-360, 2001.

54. Lee JS, Kim HS, Kim YB, Lee MC, Park CS and Min KW: Reduced PTEN expression is associated with poor outcome and angiogenesis in invasive ductal carcinoma of the breast. Appl Immunohistochem Mol Morphol 12: 205-210, 2004.

55. Steelman LS, Navolanic PM, Sokolosky ML, Taylor JR, Lehmann BD, Chappell WH, Abrams SL, Wong EW, Stadelman KM, Terrian DM, et al: Suppression of PTEN function increases breast cancer chemotherapeutic drug resistance while conferring sensitivity to mTOR inhibitors. Oncogene 27: 4086-4095, 2008.

56. Tanaka M, Koul D, Davies MA, Liebert M, Steck PA and Grossman HB: MMAC1/PTEN inhibits cell growth and induces chemosensitivity to doxorubicin in human bladder cancer cells Oncogene 19: 5406-5412, 2000.

57. Bates RC, Edwards NS, Burns GF and Fisher DE: A CD44 survival pathway triggers chemoresistance via lyn kinase and phosphoinositide 3-kinase/Akt in colon carcinoma cells. Cancer Res 61: 5275-5283, 2001.

58. Nevanlinna $\mathrm{H}$ and Bartek J: The CHEK 2 gene and inherited breast cancer susceptibility. Oncogene 25: 5912-5919, 2006.

59. Shaag A, Walsh T, Renbaum P, Kirchhoff T, Nafa K, Shiovitz S, Mandell JB, Welcsh P, Lee MK, Ellis N, et al: Functional and genomic approaches reveal an ancient CHEK2 allele associated with breast cancer in the Ashkenazi Jewish population. Hum Mol Genet 14: 555-563, 2005.

60. Abraham RT: PI 3-kinase related kinases: 'big' players in stressinduced signaling pathways. DNA Repair 3: 883-887, 2004.

61. Angele S, Romestaing P, Moullan N, Vuillaume M, Chapot B, Friesen M, Jongmans W, Cox DG, Pisani P, Gerard JP and Hall J: ATM haplotypes and cellular response to DNA damage: association with breast cancer risk and clinical radiosensitivity. Cancer Res 63: 8717-8725, 2003

62. McKinnon PJ: ATM and ataxia telangiectasia. EMBO Rep 5: $772-776,2004$
63. Milne RL: Variants in the ATM gene and breast cancer susceptibility. Genome Med 1: 12, 2009.

64. Lee JH and Paull TT: Direct activation of the ATM protein kinase by the Mre11/Rad50/Nbs1 complex. Science 304: 93-96, 2004.

65. Consortium TCBCC-C: CHEK $2 * 1100$ delC and susceptibility to breast cancer: a collaborative analysis involving 10,860 breast cancer cases and 9,065 controls from 10 studies. Am J Hum Genet 74: 1175-1182, 2004.

66. Kilpivaara O, Vahteristo P, Falck J, Syrjakoski K, Eerola H, Easton D, Bartkova J, Lukas J, Heikkila P, Aittomaki K, et al: CHEK2 variant I157T may be associated with increased breast cancer risk. Int J Cancer 111: 543-547, 2004.

67. Kleibl Z, Havranek O, Novotny J, Kleiblova P, Soucek P and Pohlreich P: Analysis of CHEK2 FHA domain in Czech patients with sporadic breast cancer revealed distinct rare genetic alterations. Breast Cancer Res Treat 112: 159-164, 2008.

68. Le GM, O'Malley CD, Glaser SL, Lynch CF, Stanford JL, Keegan TH and West DW: Breast implants following mastectomy in women with early-stage breast cancer: prevalence and impact on survival. Breast Cancer Res 7: R184-193, 2005.

69. Brown SL: Epidemiology of silicone-gel breast implants. Epidemiology 13: S34-39, 2002.

70. Bese NS, Kiel K, El-Gueddari Bel K, Campbell OB, Awuah B and Vikram B: Radiotherapy for breast cancer in countries with limited resources: program implementation and evidence-based recommendations. Breast J 12: S96-102, 2006.

71. Goss PE, Ingle JN, Martino S, Robert NJ, Muss HB, Piccart MJ, Castiglione M, Tu D, Shepherd LE, Pritchard KI, et al: Randomized trial of letrozole following tamoxifen as extended adjuvant therapy in receptor-positive breast cancer: updated findings from NCIC CTG MA.17. J Natl Cancer Inst 97: 1262-1271, 2005.

72. Crew KD, Greenlee H, Capodice J, Raptis G, Brafman L, Fuentes D, Sierra A and Hershman DL: Prevalence of joint symptoms in postmenopausal women taking aromatase inhibitors for early-stage breast cancer. J Clin Oncol 25: 3877-3883, 2007.

73. Zoli W, Ulivi P, Tesei A, Fabbri F, Rosetti M, Maltoni R, Giunchi DC, Ricotti L, Brigliadori G, Vannini I and Amadori D: Addition of 5-fluorouracil to doxorubicin-paclitaxel sequence increases caspase-dependent apoptosis in breast cancer cell lines. Breast Cancer Res 7: R681-689, 2005.

74. McArthur HL, Mahoney KM, Morris PG, Patil S, Jacks LM, Howard J, Norton L and Hudis CA: Adjuvant trastuzumab with chemotherapy is effective in women with small, node-negative, HER2-positive breast cancer. Cancer 117: 5461-5468, 2011.

75. Piccart M: The role of taxanes in the adjuvant treatment of early stage breast cancer. Breast Cancer Res Treat 79 (Suppl 1): S25-34, 2003.

76. Weiss RB, Woolf SH, Demakos E, Holland JF, Berry DA, Falkson G, Cirrincione CT, Robbins A, Bothun S, Henderson IC and Norton L: Natural history of more than 20 years of node-positive primary breast carcinoma treated with cyclophosphamide, methotrexate, and fluorouracil-based adjuvant chemotherapy: a study by the Cancer and Leukemia Group B. J Clin Oncol 21: 1825-1835, 2003

77. Hedley D, Ogilvie L and Springer C: Carboxypeptidase-G2based gene-directed enzyme-prodrug therapy: a new weapon in the GDEPT armoury. Nat Rev Cancer 7: 870-879, 2007.

78. Nawa A, Tanino T, Luo C, Iwaki M, Kajiyama H, Shibata K, Yamamoto E, Ino K, Nishiyama Y and Kikkawa F: Gene directed enzyme prodrug therapy for ovarian cancer: could GDEPT become a promising treatment against ovarian cancer? Anticancer Agents Med Chem 8: 232-239, 2008.

79. Greco O and Dachs GU: Gene directed enzyme/prodrug therapy of cancer: historical appraisal and future prospectives. J Cell Physiol 187: 22-36, 2001

80. McKeown SR, Ward C and Robson T: Gene-directed enzyme prodrug therapy: a current assessment. Curr Opin Mol Ther 6: 421-435, 2004

81. Voeks D, Martiniello-Wilks R, Madden V, Smith K, Bennetts E, Both GW and Russell PJ: Gene therapy for prostate cancer delivered by ovine adenovirus and mediated by purine nucleoside phosphorylase and fludarabine in mouse models. Gene Ther 9: 759-768, 2002.

82. Anderson WF: Gene therapy scores against cancer. Nat Med 6: $862-863,2000$

83. Chung-Faye GA, Kerr DJ, Young LS and Searle PF: Gene therapy strategies for colon cancer. Mol Med Today 6: 82-87, 2000. 
84. Schepelmann S, Hallenbeck P, Ogilvie LM, Hedley D Friedlos F, Martin J, Scanlon I, Hay C, Hawkins LK, Marais R and Springer CJ: Systemic gene-directed enzyme prodrug therapy of hepatocellular carcinoma using a targeted adenovirus armed with carboxypeptidase G2. Cancer Res 65: 5003-5008, 2005.

85. Chung-Faye GA, Chen MJ, Green NK, Burton A, Anderson D, Mautner V, Searle PF and Kerr DJ: In vivo gene therapy for colon cancer using adenovirus-mediated, transfer of the fusion gene cytosine deaminase and uracil phosphoribosyltransferase. Gene Ther 8: 1547-1554, 2001.

86. Hernandez-Alcoceba R, Sangro B and Prieto J: Gene therapy of liver cancer. World J Gastroenterol 12: 6085-6097, 2006.

87. Yi BR, O SN, Kang NH, Hwang KA, Kim SU, Jeung EB, Kim YB, Heo GJ and Choi KC: Genetically engineered stem cells expressing cytosine deaminase and interferon- $\beta$ migrate to human lung cancer cells and have potentially therapeutic antitumor effects. Int J Oncol 39: 833-839, 2011

88. Yi BR, Kang NH, Hwang KA, Kim SU, Jeung EB and Choi KC: Antitumor therapeutic effects of cytosine deaminase and interferon- $\beta$ against endometrial cancer cells using genetically engineered stem cells in vitro. Anticancer Res 31: 2853-2861, 2011.

89. Dachs GU, Hunt MA, Syddall S, Singleton DC and Patterson AV: Bystander or no bystander for gene directed enzyme prodrug therapy. Molecules 14: 4517-4545, 2009.

90.Pfeifer A and Verma IM: Gene therapy: promises and problems. Annu Rev Genomics Hum Genet 2: 177-211, 2001.

91. Shah K: Mesenchymal stem cells engineered for cancer therapy. Adv Drug Deliv Rev 64: 739-748, 2012.

92. Ramnaraine M, Pan W, Goblirsch M, Lynch C, Lewis V, Orchard P, Mantyh P and Clohisy DR: Direct and bystander killing of sarcomas by novel cytosine deaminase fusion gene. Cancer Res 63: 6847-6854, 2003.

93. Nyati MK, Symon Z, Kievit E, Dornfeld KJ, Rynkiewicz SD, Ross BD, Rehemtulla A and Lawrence TS: The potential of 5 -fluorocytosine/cytosine deaminase enzyme prodrug gene therapy in an intrahepatic colon cancer model. Gene Ther 9: 844-849, 2002.

94. Ireton GC, Black ME and Stoddard BL: Crystallization and preliminary X-ray analysis of bacterial cytosine deaminase. Acta Crystallogr D Biol Crystallogr 57: 1643-1645, 2001.

95. Ireton GC, Black ME and Stoddard BL: The 1.14 A crystal structure of yeast cytosine deaminase: evolution of nucleotide salvage enzymes and implications for genetic chemotherapy. Structure 11: 961-972, 2003.

96. Denny WA: Prodrugs for Gene-Directed Enzyme-Prodrug Therapy (Suicide Gene Therapy). J Biomed Biotechnol 2003 48-70, 2003

97. Ireton GC, McDermott G, Black ME and Stoddard BL: The structure of Escherichia coli cytosine deaminase. J Mol Biol 315: 687-697, 2002.

98. Fuchita M, Ardiani A, Zhao L, Serve K, Stoddard BL and Black ME: Bacterial cytosine deaminase mutants created by molecular engineering show improved 5-fluorocytosine-mediated cell killing in vitro and in vivo. Cancer Res 69: 4791-4799, 2009.

99. Kim KY, Kim SU, Leung PC, Jeung EB and Choi KC: Influence of the prodrugs 5-fluorocytosine and CPT-11 on ovarian cancer cells using genetically engineered stem cells: tumor-tropic potential and inhibition of ovarian cancer cell growth. Cancer Sci 101: 955-962, 2010

100. Chen JK, Hu LJ, Wang D, Lamborn KR and Deen DF: Cytosine deaminase/5-fluorocytosine exposure induces bystander and radiosensitization effects in hypoxic glioblastoma cells in vitro. Int J Radiat Oncol Biol Phys 67: 1538-1547, 2007.

101. Miller CR, Williams CR, Buchsbaum DJ and Gillespie GY: Intratumoral 5-fluorouracil produced by cytosine deaminase/5fluorocytosine gene therapy is effective for experimental human glioblastomas. Cancer Res 62: 773-780, 2002.

102. Humerickhouse R, Lohrbach K, Li L, Bosron WF and Dolan ME: Characterization of CPT-11 hydrolysis by human liver carboxylesterase isoforms hCE-1 and hCE-2. Cancer Res 60: 1189-1192, 2000.

103. Bencharit S, Morton CL, Howard-Williams EL, Danks MK, Potter PM and Redinbo MR: Structural insights into CPT-11 activation by mammalian carboxylesterases. Nat Struct Biol 9: 337-342, 2002.

104. Bodor N and Buchwald P: Soft drug design: general principles and recent applications. Med Res Rev 20: 58-101, 2000.
105. Wadkins RM, Morton CL, Weeks JK, Oliver L, Wierdl M, Danks MK and Potter PM: Structural constraints affect the metabolism of 7-ethyl-10-[4-(1-piperidino)-1-piperidino] carbonyloxycamptothecin (CPT-11) by carboxylesterases. Mo Pharmacol 60: 355-362, 2001

106. Wierdl M, Morton CL, Weeks JK, Danks MK, Harris LC and Potter PM: Sensitization of human tumor cells to CPT-11 via adenoviral-mediated delivery of a rabbit liver carboxylesterase. Cancer Res 61: 5078-5082, 2001.

107. Kojima A, Hackett NR, Ohwada A and Crystal RG: In vivo human carboxylesterase cDNA gene transfer to activate the prodrug CPT-11 for local treatment of solid tumors. J Clin Invest 101: 1789-1796, 1998

108. van Dillen IJ, Mulder NH, Vaalburg W, de Vries EF and Hospers GA: Influence of the bystander effect on HSV-tk/GCV gene therapy. A review. Curr Gene Ther 2: 307-322, 2002.

109. Gerolami R, Cardoso J, Lewin M, Bralet MP, Sa Cunha A, Clement O, Brechot $\mathrm{C}$ and Tran PL: Evaluation of HSV-tk gene therapy in a rat model of chemically induced hepatocellular carcinoma by intratumoral and intrahepatic artery routes. Cancer Res 60: 993-1001, 2000.

110. Fillat C, Carrio M, Cascante A and Sangro B: Suicide gene therapy mediated by the Herpes Simplex virus thymidine kinase gene/Ganciclovir system: fifteen years of application. Curr Gene Ther 3: 13-26, 2003.

111. Huang Q, Pu P, Xia Z and You Y: Exogenous wt-p53 enhances the antitumor effect of HSV-TK/GCV on C6 glioma cells. J Neurooncol 82: 239-248, 2007.

112. Cowen RL, Williams JC, Emery S, Blakey D, Darling JL, Lowenstein PR and Castro MG: Adenovirus vector-mediated delivery of the prodrug-converting enzyme carboxypeptidase G2 in a secreted or GPI-anchored form: High-level expression of this active conditional cytotoxic enzyme at the plasma membrane. Cancer Gene Ther 9: 897-907, 2002.

113. Muller FJ, Snyder EY and Loring JF: Gene therapy: can neural stem cells deliver? Nat Rev Neurosci 7: 75-84, 2006.

114. Kim SU, Jeung EB, Kim YB, Cho MH and Choi KC: Potential tumor-tropic effect of genetically engineered stem cells expressing suicide enzymes to selectively target invasive cancer in animal models. Anticancer Res 31: 1249-1258, 2011.

115. Tang Y, Shah K, Messerli SM, Snyder E, Breakefield X and Weissleder R: In vivo tracking of neural progenitor cell migration to glioblastomas. Hum Gene Ther 14: 1247-1254, 2003.

116. Power AT and Bell JC: Cell-based delivery of oncolytic viruses: a new strategic alliance for a biological strike against cancer. Mol Ther 15: 660-665, 2007.

117. Kim KY, Yi BR, Lee HR, Kang NH, Jeung EB, Kim SU and Choi KC: Stem cells with fused gene expression of cytosine deaminase and interferon- $\beta$ migrate to human gastric cancer cells and result in synergistic growth inhibition for potential therapeutic use. Int J Oncol 40: 1097-1104, 2012.

118. Aboody KS, Najbauer J and Danks MK: Stem and progenitor cell-mediated tumor selective gene therapy. Gene Ther 15: 739-752, 2008

119. Gutova M, Najbauer J, Frank RT, Kendall SE, Gevorgyan A, Metz MZ, Guevorkian M, Edmiston M, Zhao D, Glackin CA, et al: Urokinase plasminogen activator and urokinase plasminogen activator receptor mediate human stem cell tropism to malignant solid tumors. Stem Cells 26: 1406-1413, 2008.

120. Bithell A and Williams BP: Neural stem cells and cell replacement therapy: making the right cells. Clin Sci 108: 13-22, 2005

121. Kim SK, Kim SU, Park IH, Bang JH, Aboody KS, Wang KC, Cho BK, Kim M, Menon LG, Black PM and Carroll RS: Human neural stem cells target experimental intracranial medulloblastoma and deliver a therapeutic gene leading to tumor regression. Clin Cancer Res 12: 5550-5556, 2006.

122. Sohur US, Emsley JG, Mitchell BD and Macklis JD: Adult neurogenesis and cellular brain repair with neural progenitors, precursors and stem cells. Philos Trans R Soc Lond B Biol Sci 361: 1477-1497, 2006

123. Kim SU, Park IH, Kim TH, Kim KS, Choi HB, Hong SH, Bang JH, Lee MA, Joo IS, Lee CS and Kim YS: Brain transplantation of human neural stem cells transduced with tyrosine hydroxylase and GTP cyclohydrolase 1 provides functional improvement in animal models of Parkinson disease. Neuropathology 26: 129-140, 2006.

124. Joo KM, Park IH, Shin JY, Jin J, Kang BG, Kim MH, Lee SJ, Jo MY, Kim SU and Nam DH: Human neural stem cells can target and deliver therapeutic genes to breast cancer brain metastases. Mol Ther 17: 570-575, 2009. 